\title{
The real-world efficacy and safety of anlotinib in advanced non-small cell lung cancer
}

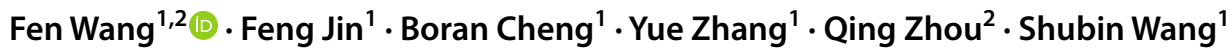

Received: 26 February 2021 / Accepted: 1 August 2021 / Published online: 6 August 2021

(c) The Author(s), under exclusive licence to Springer-Verlag GmbH Germany, part of Springer Nature 2021

\begin{abstract}
Purpose Anlotinib is an anti-angiogenetic multi-targeted tyrosine kinase inhibitor. This study aimed to evaluate the efficacy and safety of anlotinib in advanced non-small cell lung cancer (aNSCLC) in the real world.

Methods Patients with aNSCLC receiving anlotinib were enrolled in two cohorts (treatment naive and previously treated). The endpoints included progression-free survival (PFS), overall survival (OS) and anlotinib-related adverse events (ar-AEs). Results 203 patients accrued in the study. In the treatment-naïve cohort $(n=80)$, the PFS was 7.4 (95\% confidence interval [CI] 4.1-10.7) and OS was 10.8 (95\% CI 5.8-15.8) months of monotherapy group (immature survival for combination group). In previously treated cohort ( $n=123)$, the PFS was 8.0 months (95\% CI 6.1-9.9) in the combination group and 4.3 months (95\% CI 2.1-6.6) in the monotherapy group (hazard ratio [HR] 0.49; 95\% CI $0.29-0.83 ; p=0.007$ ), respectively. The OS was 18.5 months (95\% CI 10.5-26.6) in the combination group and 7.8 months (95\% CI 7.1-8.4) in the monotherapy group (HR 0.38; 95\% CI $0.22-0.66 ; p=0.001$ ), respectively. The ar-AEs of grade $\geq 3$ in the monotherapy and the combination groups were hypertension (9.0 and 8.7\%), fatigue (8.1 and 7.6\%), hand-foot syndrome (8.1 and 6.5\%), diarrhea (5.4 and $8.7 \%$ ), proteinuria (5.4 and $5.4 \%$ ), and mucositis oral (6.3 and $8.7 \%$ ).

Conclusion In aNSCLC, anlotinib monotherapy has a promising efficacy in the first-line setting. It may be an option for those who are ineligible for chemotherapy; anlotinib combination therapy in a $\geq$ second-line setting showed manageable toxicities and encouraging efficacy, indicating a good application prospect.

Trial registration This study was retrospectively registered with ISRCTN Registry (ID ISRCTN35543977) on January 26th, 2021 and Chinese Clinical Trial Register (ChiCTR2000032265) on April 4th, 2020.
\end{abstract}

Keywords Anlotinib $\cdot$ Non-small cell lung cancer $\cdot$ Real world $\cdot$ Tyrosine kinase inhibitor $\cdot$ Anti-angiogenesis

\section{Introduction}

Fen Wang

fina_wang@163.com

1 Department of Oncology, Shenzhen Key Laboratory of Gastrointestinal Cancer Translational Research, Cancer Institute, Peking University Shenzhen Hospital, ShenzhenPeking University-Hong Kong University of Science and Technology Medical Center, No. 1120 Lianhua Road, Futian District, Shenzhen 518036, Guangdong, China

2 Guangdong Lung Cancer Institute, Guangdong Provincial Key Laboratory of Translational Medicine in Lung Cancer, Guangdong Provincial People's Hospital, The Second School of Clinical Medicine, Southern Medical University, Guangzhou, Guangdong, China
Non-small cell lung cancer (NSCLC) is the commonest type of lung cancer and comprises $83 \%$ of all lung cancers (Miller et al. 2019), with $\geq 50 \%$ of cases diagnosed at advanced stages (Siegel et al. 2019). Following the increased understanding of the molecular and immunologic profiles of lung cancer and advances in targeted therapy and immunotherapy, the treatment of advanced NSCLC (aNSCLC) has greatly advanced in the last 20 years. The 5-year overall survival (OS) of patients with aNSCLC has greatly improved with the use of these agents (Garon et al. 2019; Gettinger et al. 2018; Lin et al. 2016; Mok et al. 2009; Ramalingam et al. 2020).

Anti-angiogenesis therapy remains indispensable in the standard care for aNSCLC since it normalizes the tumor vasculature and suppresses the tumor microenvironment. The 
standard first-line treatment for aNSCLC without oncogenic driver mutations in China is platinum-based chemotherapy (Barlesi et al. 2014; Sandler et al. 2006; Zhou et al. 2015), or in combination with bevacizumab, if non-squamous (Fossella et al. 2003; Scagliotti et al. 2008; Schiller et al. 2002). Initial chemotherapy combined with a programmed death-ligand 1 (PD-L1) inhibitor has not proven to be more beneficial than a combination with bevacizumab (Socinski et al. 2021). In patients with epidermal growth factor receptor (EGFR)-mutated aNSCLC, a combination of antiangiogenesis therapy and EGFR-tyrosine kinase inhibitors (TKIs) has improved patient survival than EGFR-TKI alone (Nakagawa et al. 2019; Saito et al. 2019; Zhou et al. 2019).

Anlotinib is an oral small molecular multi-targeted TKI with anti-angiogenic (by inhibiting vascular endothelial growth factor receptor 1-3 and fibroblast growth factor receptor 1-4) and anti-tumor proliferation properties (by inhibiting platelet-derived growth factor receptor $\alpha$ and $\beta$, RET, and stem cell factor receptor) (Lin et al. 2018; Sun et al. 2016; Xie et al. 2018). It has been approved by the National Medical Products Administration of China for $\geq$ third-line treatment of aNSCLC (Han et al. 2018) and advanced small cell lung cancer (Cheng et al. 2018).

Notably, substantial differences exist between patients in clinical trials and in the real world, particularly those with poor conditions (e.g., the elderly, patients with a performance status $[\mathrm{PS}] \geq 2$, brain metastases, and comorbidities) (Nabhan et al. 2019). However, anlotinib may be preferred in clinical practice for patients with aNSCLC who are not eligible or unwilling to receive standard care. Several preclinical and clinical trials have confirmed the synergy between antiangiogenesis therapy and chemotherapy, targeted therapy and immunotherapy, providing a rationale for a combination therapy strategy with these regimens (Alshangiti et al. 2018). Furthermore, oral anlotinib therapy during the coronavirus disease (COVID-19) pandemic has several advantages such as reducing the number of in-person visits or invasive procedures. Therefore, we investigated the efficacy and safety of anlotinib when used alone or with other antineoplastic agents in patients with aNSCLC in a real-world setting. This is the first of such studies.

\section{Materials and methods}

\section{Study design and patients}

This was a retrospective observational cohort study conducted at Peking University Shenzhen Hospital, a universityaffiliated tertiary hospital located in Guangdong, China.

Adult (age $\geq 18$ years) patients treated with anlotinib or anlotinib-containing regimens between 1 June 2018 and 30 September 2020 were identified through electronic medical order system (EMS). Patients were screened if they had pathologically confirmed stage IIIB to IV or recurrent NSCLC, measurable disease as evaluated based on Response Evaluation Criteria in Solid Tumours (RECIST, version 1.1) (Eisenhauer et al. 2009), adequate organs function and a performance status of $0-3$. Eligible patients were enrolled in treatment-naïve cohort and previously treated cohort. Each cohort was divided into two groups, monotherapy and combination therapy. Exclusion criteria included, incomplete treatment information, local treatment including interventional therapy and radiotherapy for the target lesions during anlotinib treatment, and malignancies other than lung cancer within 5 years (except those treated with curative intent and had negligible risk of death or metastases, according to the discretion of primary investigator).

\section{Procedure}

Anlotinib was administered orally once daily at an initial dose from 10 to $12 \mathrm{mg}$ on day 1 to day 14 of a 21-day cycle. The initial dose and combined regimen were decided by the physicians. Anlotinib was continued until tumour progression, death, unacceptable toxicity, and could continue beyond radio-imaging progression for as long as clinical benefit was observed in the absence of symptomatic deterioration and unacceptable toxicity, as judged by the physicians. Dose reductions or suspension were allowed if patients had a $\geq$ grade 3 anlotinib-related adverse events (ar-AEs). If arAEs resolved or reverted to $\leq$ grade 2 within 2 weeks, anlotinib was re-administrated at the same dose or a lower dose. Where ar-AEs persisted after 2-week interruption, anlotinib was discontinued permanently.

Tumor responses were assessed based on RECIST 1.1 every 6 weeks in the first 6 cycles and every 8 weeks subsequently until confirmed disease progression. Clinical followup was done regularly every $6-8$ weeks when the patients visited clinic for the prescription of anlotinib. The survival follow-up was performed by telephone every 3 months after disease progression. Ar-AEs were categorised and graded according to the National Cancer Institute-Common Terminology Criteria for Adverse Events (NCI-CTCAE, version 4.03).

The EMS was used to collect baseline characteristics, laboratory data, AEs and outcomes. Baseline characteristics included gender, age, smoking status, Eastern Cooperative Oncology Group (ECOG) PS, pathological type, date of diagnosis of advanced disease, disease stage, metastases site, comorbidity and complication, medical histology, presence of oncogenic diver mutations (EGFR, ROS-1, RET, ALK, KRAS, BRAF, c-MET, HER2), prior and subsequent systematic treatment, and best tumor response. The biochemical parameter values and blood cell counts were collected at baseline and during anlotinib treatment. 


\section{Outcomes}

The primary endpoint was progression-free survival (PFS) and secondary endpoints included objective response rate (ORR), disease control rate (DCR), time to treatment failure (TTF), overall survival (OS), and toxicity. The exploratory endpoint was potential biomarker analysis for anlotinib first-line monotherapy. The type of combined agents was the major stratification factor used to analyze the efficacy of later-line anlotinib-combined therapy.

The PFS was defined as the time from the first anlotinib administration to the documented radio-imaging progression or death due to any cause. The ORR and DCR was defined as the percentage of patients with at least one confirmed response and response plus stable disease before any evidence of progression, respectively. TTF was defined as a composite endpoint measuring time from the first anlotinib administration to discontinuation of treatment for any reason, including disease progression, treatment toxicity, and death. OS was defined as the time from the first anlotinib administration to death from any cause or last follow-up. Ar-AEs, including events that led to dose reductions, treatment discontinuation, or death, were collected. Lymphocyte to monocyte ratio (LMR), neutrophil to lymphocyte ratio (NLR), platelet to lymphocyte ratio (PLR), and prognostic nutritional index (PNI, as calculated as $10 \times$ albumin level $(\mathrm{g} / \mathrm{dl})+0.005 \times$ total lymphocyte count $\left(\right.$ per $\left.\mathrm{mm}^{3}\right)$ (Wang et al. 2018) were calculated based on the baseline laboratory data.

\section{Statistical analysis}

Patients' baseline characteristics were reported with descriptive statistics as proportions for categorical variables and medians (range) for continuous variables. Pearson's Chisquare test or Fisher's exact test were used to compare categorical variables and tumour responses between two groups. A $p$-value of $<0.05$ was considered statistically significant. The median follow-up period was computed based on the reverse Kaplan-Meier method. The median PFS, OS and 95\% confidence interval (CI) were estimated using the Kaplan-Meier method, with differences between groups being evaluated using the log-rank test. Cox proportional hazards regression was used for the univariable and multivariable analysis of PFS and OS and to calculate the hazard ratios (HR) with 95\% CIs. To assess the predictive accuracy of the biomarkers in the exploratory analysis, time-dependent receiver operating characteristic (ROC) were constructed using R software. All statistical analyses were performed using the statistical package for the social sciences (SPSS) software version 23 (SPSS Inc., Chicago,
IL, USA) and R software version 4.0 (The R foundation for statistical computing, Vienna, Austria).

\section{Ethical approval and informed consent}

The study was approved by the China Ethics Committee of Registering Clinical Trials (No. ChiECRCT20200083) and performed in accordance with Good Clinical Practice and the provisions of the Declaration of Helsinki. Written informed consent was waived given the nature of the study.

\section{Results}

\section{Patients and treatment}

From June 1, 2018, to September 30, 2020, 226 patients were screened from the EMS. A total of 203 patients were enrolled: 80 in the treatment-naïve cohort and 123 in the previously treated cohort (Fig. 1). The median follow-up duration was 11.0 (range 7.1-14.8) months and 10.0 (range 8.8-11.8) months, respectively.

Details of the patients' characteristics are shown in Table 1. Patients aged $\geq 75$ years $(22$ [27.5\%] and 15 [12.2\%], respectively), with a PS $\geq 2$ (28 [35.0\%] and 40 [32.5\%], respectively), and with central nervous system metastases (7 [8.8\%] and 23 [18.7\%], respectively) were also enrolled, although patients with these characteristics are usually under-represented in clinical trials. There were more male patients $(84.6 \%$ vs. $60.7 \%, p=0.017)$ in the treatmentnaïve monotherapy group than in the combination group, and more patients with a PS $\geq 2(44.1 \%$ vs. $21.9 \%, p=0.009)$ in the previously treated monotherapy group.

\section{PFS, OS and TTF}

In the treatment-naïve cohort, 22 events of disease progression or death occurred in the monotherapy group and 5 in the combination group, respectively; 35 and 1 deaths occurred in the monotherapy and combination groups, respectively. Given the limited events of the combination group in this cohort, we analyzed the survival of the monotherapy group only. The median PFS was 7.4 (95\% confidence interval [CI] 4.1-10.7) months and the median OS was 10.8 (95\% CI 5.8-15.8) months in the treatment-naïve monotherapy group (Fig. 2). The median TTF was 8.2 (95\% CI 4.3-12.0) months (Supplementary Figure 1A).

In the previously treated cohort, 63 events of disease progression or death occurred. The median PFS was 8.0 (95\% CI 6.1-9.9) months in the combination group and 4.3 (95\% CI 2.1-6.6) months in the monotherapy group (hazard ratio [HR] 0.49; 95\% CI 0.29-0.83; $p=0.007$ ), respectively (Fig. 3A). The HR for PFS was less than 1.00 across 
Fig. 1 CONSORT diagram of the study population selection for advanced non-small cell lung cancer (NSCLC) $(n[\%])$

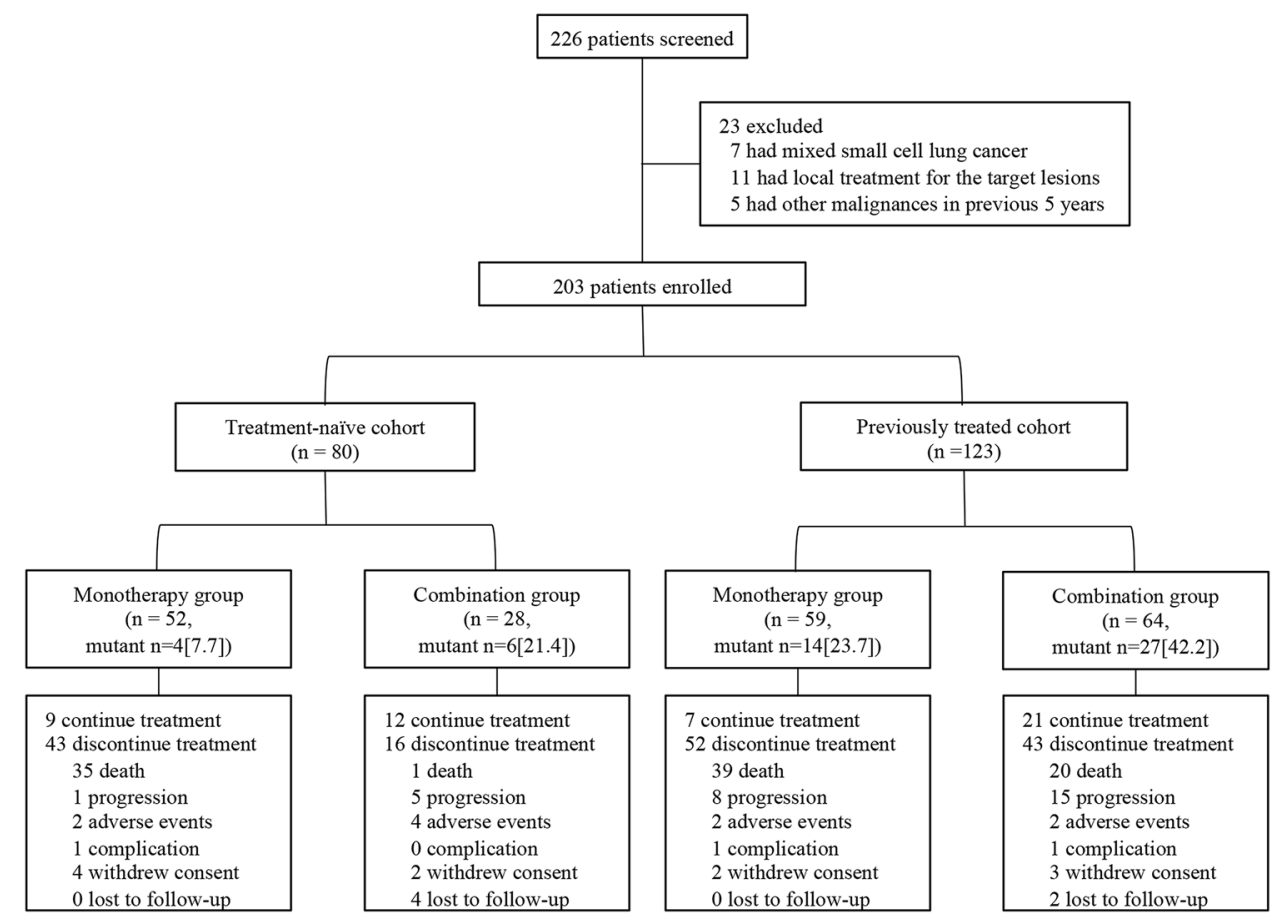

almost all subgroups except for the patients with a PS $\geq 2$ and harbouring driver mutations (Fig. 3B). However, the upper boundaries of the $95 \%$ CI crossed 1.00 for multiple subgroups. The interaction test showed that the treatment efficacy varied significantly only across the subgroups of histology types (non-squamous vs. squamous, $p=0.045$ ) and driver mutations (yes vs. no, $p=0.034$ ).

With 59 deaths, the median OS was 18.5 (95\% CI 10.5-26.6) months in the combination group and $7.8(95 \%$ CI 7.1-8.4) months in the monotherapy group (HR 0.38; 95\% CI 0.22-0.66; $p=0.001$ ), respectively (Fig. 4A). Consistent with PFS, the OS benefit of the combination was observed in all subgroups (Fig. 4B), yet with the upper boundaries of the $95 \%$ CIs crossing 1.00 in multiple subgroups. No statistical differences in treatment efficacy comparing combination with monotherapy were observed among subgroups in the interaction test. The PFS and OS did not differ among patients who received different anlotinib-combined agents (median PFS, ICIs vs. TKIs vs. chemotherapy: 18.2 vs. 7.6 vs. 8.0 months, $p=0.483$; median OS, ICIs vs. TKIs vs. chemotherapy: 18.5 vs. not reached [NR] vs. 19.6 months, $p=0.348$ ) (Fig. 5A, B). In the multivariate analysis, the combination $(p=0.044)$ and the prior anti-angiogenesis treatment $(p=0.013)$ were statistically associated with the PFS; whereas only the combination ( $p=0.010)$ was statistically associated with the OS (Supplementary Table 1).
The median TTF was 9.5 (95\% CI 6.5-12.5) months in the combination group and $6.3(95 \% \mathrm{CI} 4.0-8.4)$ months in the monotherapy group (HR $0.48 ; 95 \%$ CI $0.26-0.89$; $p=0.019$ ), respectively (Supplementary Figure 1B).

\section{Tumor response}

In the treatment-naïve cohort, no patient in the monotherapy group and one patient in the combination group achieved a complete response (CR); 7 and 11 achieved a partial response (PR) in the two groups, respectively. The ORR was significantly higher in the combination group than that in the monotherapy group ( $42.9 \%$ vs. $13.5 \%, p=0.004$ ); while the DCR was only numerically higher without a statistical difference (82.1\% vs. $73.1 \%, p=0.197)$ (Table 2).

In the previously treated cohort, more patients responded to anlotinib combination therapy, with 1 (1.6\%) CR case and 18 (28.1\%) PR cases, respectively. There were significant differences in both ORR and DCR between the combination and monotherapy groups (ORR $29.7 \%$ vs. 6.8\%, $p=0.002$; DCR $81.4 \%$ vs. $59.3 \%, p=0.025$ ) (Table 2).

\section{Exploratory analysis}

In the treatment-naïve monotherapy group, the potential predictive and prognostic value of patients' characteristics and several laboratory parameters, including NLR, LMR, PLR, and PNI, were analyzed. No clinical characteristics 
Table 1 Patient baseline characteristics in two cohorts

\begin{tabular}{|c|c|c|c|c|c|c|c|c|}
\hline \multirow{2}{*}{$\begin{array}{l}\text { Characteristics, } \\
n(\%)\end{array}$} & \multicolumn{4}{|c|}{ Treatment-naïve cohort } & \multicolumn{4}{|c|}{ Previously treated cohort } \\
\hline & Overall $(n=80)$ & $\begin{array}{l}\text { Monotherapy } \\
(n=52)\end{array}$ & $\begin{array}{l}\text { Combination } \\
(n=28)\end{array}$ & $p$ & $\begin{array}{l}\text { Overall } \\
(n=123)\end{array}$ & $\begin{array}{l}\text { Monotherapy } \\
(n=59)\end{array}$ & $\begin{array}{l}\text { Combination } \\
(n=64)\end{array}$ & $p$ \\
\hline \multicolumn{9}{|l|}{ Age (years) } \\
\hline Median (range) & $68(42-88)$ & $69(46-88)$ & $65(42-83)$ & 0.655 & $64(32-87)$ & $65(37-81)$ & $63(32-87)$ & 0.257 \\
\hline$<70$ & $43(53.8)$ & $27(51.9)$ & $16(57.1)$ & & $99(80.5)$ & $45(76.3)$ & $54(84.4)$ & \\
\hline$\geq 70$ & $37(46.3)$ & $25(48.1)$ & $12(42.9)$ & & $24(19.5)$ & $14(23.7)$ & $10(15.6)$ & \\
\hline$\geq 75$ & $22(27.5)$ & $18(34.6)$ & $4(14.3)$ & & $15(12.2)$ & $10(16.9)$ & $5(7.8)$ & \\
\hline Sex & & & & 0.017 & & & & 0.957 \\
\hline Male & $61(76.3)$ & $44(84.6)$ & $17(60.7)$ & & $92(74.8)$ & $44(74.6)$ & $48(75.0)$ & \\
\hline Female & $19(23.8)$ & $8(15.4)$ & $11(39.3)$ & & $31(25.2)$ & $15(25.4)$ & $16(25.0)$ & \\
\hline $\begin{array}{l}\text { ECOG perfor- } \\
\text { mance status }\end{array}$ & & & & 0.169 & & & & 0.009 \\
\hline $0-1$ & $52(65.0)$ & $31(59.6)$ & $21(75.0)$ & & $83(67.5)$ & $33(55.9)$ & $50(78.1)$ & \\
\hline$\geq 2$ & $28(35.0)$ & $21(40.4)$ & $7(25.0)$ & & $40(32.5)$ & $26(44.1)$ & $14(21.9)$ & \\
\hline Smoking status & & & & 0.263 & & & & 0.218 \\
\hline Never & $32(40.0)$ & $22(42.3)$ & $10(35.7)$ & & $54(43.9)$ & $30(50.8)$ & $24(37.5)$ & \\
\hline Ever & $37(46.3)$ & $21(40.4)$ & $16(57.1)$ & & $57(46.3)$ & $25(42.4)$ & $32(50.0)$ & \\
\hline Unknown & $11(13.8)$ & $9(17.3)$ & $2(7.1)$ & & $12(9.8 \%)$ & $4(6.8)$ & $8(12.5)$ & \\
\hline Histology & & & & 0.670 & & & & 0.222 \\
\hline Non-squamous & $42(52.5)$ & $27(51.9)$ & $15(53.6)$ & & $93(75.6)$ & 43 (72.9) & $50(78.1)$ & \\
\hline Squamous & $32(40.0)$ & $22(42.3)$ & $10(35.7)$ & & $25(20.3)$ & $15(25.4)$ & $10(15.6)$ & \\
\hline Other/unknown & $6(7.5)$ & $3(5.8)$ & $3(10.7)$ & & $5(4.1)$ & $1(1.7)$ & $4(6.3)$ & \\
\hline Driver mutations & & & & 0.167 & & & & 0.063 \\
\hline Yes & $10(12.5)$ & $4(7.7)$ & $6(21.4)$ & & $41(33.3)$ & $14(23.7)$ & $27(42.2)$ & \\
\hline EGFR mutation & $6(7.5)$ & $2(3.8)$ & $4(14.3)$ & & $37(30.1)$ & $14(23.7)$ & $23(35.9)$ & \\
\hline RET fusion & $1(1.3)$ & $1(1.9)$ & $0(0)$ & & $0(0)$ & $0(0)$ & $0(0)$ & \\
\hline KRAS mutation & $2(2.5)$ & $1(1.9)$ & $1(3.6)$ & & $2(1.6)$ & $0(0)$ & $2(3.1)$ & \\
\hline BRAF mutation & $1(1.3)$ & $0(0)$ & $1(3.6)$ & & $0(0)$ & $0(0)$ & $0(0)$ & \\
\hline HER2 mutation & $0(0)$ & $0(0)$ & $0(0)$ & & $2(1.6)$ & $0(0)$ & $2(3.1)$ & \\
\hline $\begin{array}{l}\text { MET } \\
\text { amplification }^{\mathrm{a}}\end{array}$ & $0(0)$ & $0(0)$ & $1(3.6)$ & & $0(0)$ & $0(0)$ & $0(0)$ & \\
\hline No & $69(86.3)$ & 47 (90.4) & $22(78.6)$ & & $81(65.9)$ & $44(74.6)$ & $37(57.8)$ & \\
\hline Unknown & $1(1.3)$ & $1(1.3)$ & $0(0)$ & & $1(0.8)$ & $1(1.7)$ & $0(0)$ & \\
\hline Stage & & & & 0.310 & & & & 0.646 \\
\hline IIIB/IIIC & $8(10.0)$ & $7(13.5)$ & $1(3.6)$ & & $12(9.8)$ & $5(8.5)$ & 7 (10.9) & \\
\hline IV/recurrent & $72(90.0)$ & $45(86.5)$ & $27(96.4)$ & & $111(90.2)$ & $54(91.5)$ & $57(89.1)$ & \\
\hline $\begin{array}{l}\text { Number of meta- } \\
\text { static sites }\end{array}$ & & & & 0.813 & & & & 0.236 \\
\hline$<3$ & $39(48.8)$ & $24(46.2)$ & $15(53.6)$ & & 39 (31.7) & $23(39.0)$ & $16(25.0)$ & \\
\hline$\geq 3$ & $32(40.0)$ & $22(42.3)$ & $10(35.7)$ & & $71(57.7)$ & $31(52.5)$ & $40(62.5)$ & \\
\hline Other/unknown & $9(11.2)$ & $6(11.5)$ & $3(10.7)$ & & $13(10.6)$ & $5(8.5)$ & $8(12.5)$ & \\
\hline CNS metastasis & & & & 0.967 & & & & 0.347 \\
\hline Yes & $7(8.8)$ & $4(7.7)$ & $3(10.7)$ & & $23(18.7)$ & $9(15.3)$ & $14(21.9)$ & \\
\hline No & $73(91.3)$ & $48(92.3)$ & $25(89.3)$ & & $100(81.3)$ & $50(84.7)$ & $50(78.1)$ & \\
\hline $\begin{array}{l}\text { Anlotinib initial } \\
\text { dose }\end{array}$ & & & & 1.000 & & & & 0.709 \\
\hline $12 \mathrm{mg}$ & 75 (93.8) & $49(94.2)$ & $26(92.9)$ & & $116(94.3)$ & $55(93.2)$ & $61(95.3)$ & \\
\hline $10 \mathrm{mg}$ & $5(6.3)$ & $3(5.8)$ & $2(7.1)$ & & $7(5.7)$ & $4(6.8)$ & $3(4.7)$ & \\
\hline Combined agents & - & - & & & - & - & & \\
\hline ICIs & & & $18(64.3)$ & & & & $27(42.2)$ & \\
\hline
\end{tabular}


Table 1 (continued)

\begin{tabular}{|c|c|c|c|c|c|c|c|c|}
\hline \multirow{2}{*}{$\begin{array}{l}\text { Characteristics, } \\
n(\%)\end{array}$} & \multicolumn{4}{|c|}{ Treatment-naïve cohort } & \multicolumn{4}{|c|}{ Previously treated cohort } \\
\hline & Overall $(n=80)$ & $\begin{array}{l}\text { Monotherapy } \\
(n=52)\end{array}$ & $\begin{array}{l}\text { Combination } \\
(n=28)\end{array}$ & $p$ & $\begin{array}{l}\text { Overall } \\
(n=123)\end{array}$ & $\begin{array}{l}\text { Monotherapy } \\
(n=59)\end{array}$ & $\begin{array}{l}\text { Combination } \\
(n=64)\end{array}$ & $p$ \\
\hline TKIs & & & $5(17.9)$ & & & & $18(28.1)$ & \\
\hline Chemotherapy & & & $5(17.9)$ & & & & $19(29.7)$ & \\
\hline $\begin{array}{l}\text { Number of anlo- } \\
\text { tinib lines }\end{array}$ & - & - & - & & & & & 0.465 \\
\hline 2 & & & & & $48(39.0)$ & $25(42.4)$ & $23(35.9)$ & \\
\hline$\geq 3$ & & & & & $75(61.0)$ & $34(57.6)$ & $41(64.1)$ & \\
\hline $\begin{array}{l}\text { Prior anti-angio- } \\
\text { genesis }\end{array}$ & - & - & - & & & & & 0.065 \\
\hline Yes & & & & & $50(40.7)$ & $29(49.2)$ & $21(32.8)$ & \\
\hline No & & & & & $73(59.3)$ & $30(50.8)$ & $43(67.2)$ & \\
\hline
\end{tabular}

ECOG Eastern Cooperative Oncology Group, EGFR epidermal growth factor receptor, ICI immune checkpoint inhibitor, TKI tyrosine kinase inhibitor, $C N S$ central nervous system, - not applicable

${ }^{\mathrm{a}}$ One patient harboured KRAS mutation and MET amplification simultaneously
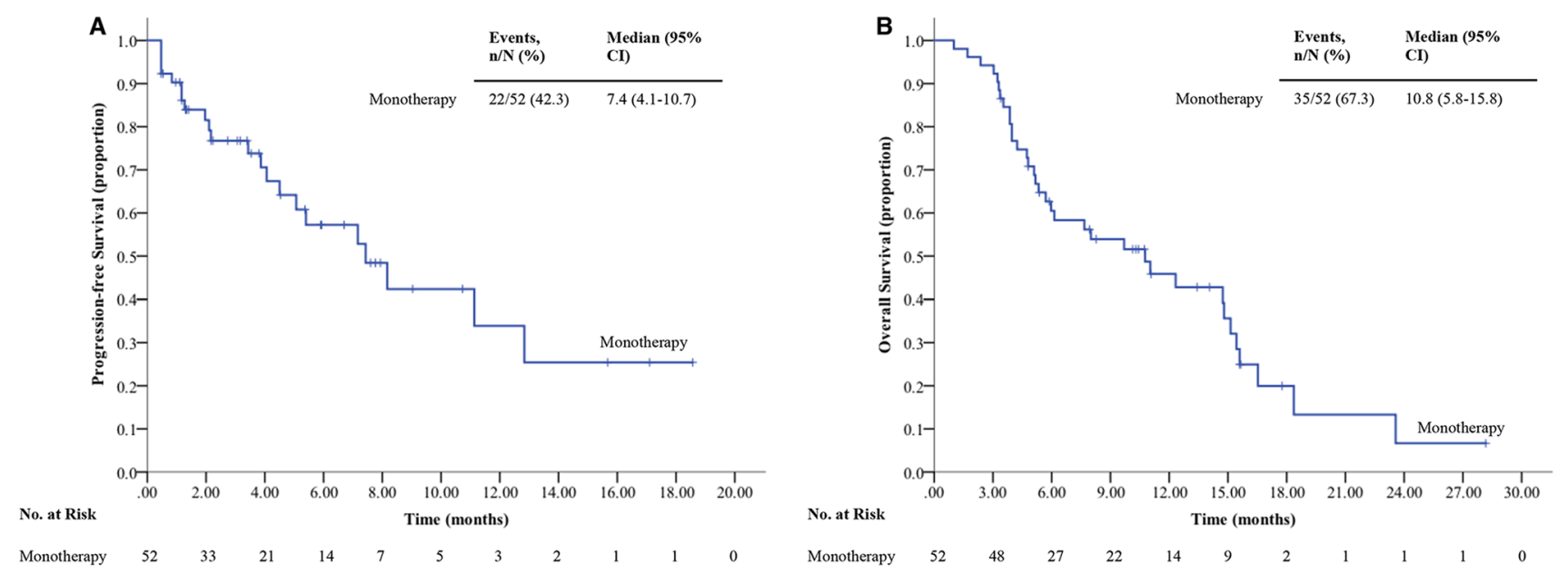

Fig. 2 Kaplan-Meier curve for progression-free survival (A) and overall survival (B) in the treatment-naïve monotherapy population. CI confidence interval

were significantly associated with PFS or OS in the univariate analysis (Supplementary Table 2). The median baseline values of these parameters (NLR 4.1, LMR 2.2, PLR 188.3, PNI 39.9) were used as cut-off values to distinguish between patients with low and high values. Notably, high baseline LMR was significantly associated with improved PFS (HR 0.37; 95\% CI 0.14-0.99; $p=0.048$ ), while high PNI was associated with longer OS (HR 0.33; 95\% CI 0.14-0.76; $p=0.009$ ) (Supplementary Table 2). NLR and PLR were not significantly associated with PFS and OS. Only high PNI was statistically associated with improved OS (HR 0.34; 95\% CI 0.13-0.90; $p=0.030$ ) in the multivariate analysis using the previous factors (data not shown). The time-dependent ROC curves at 6 and 12 months for PNI in predicting OS and LMR in predicting PFS are shown in Supplementary Figure 2A and B, respectively. The $\mathrm{C}$-index of PNI in predicting OS was 0.649 and LMR in predicting PFS was 0.652 , respectively.

\section{Safety analysis}

The toxicity of monotherapy $(n=111)$ and combination therapy $(n=92)$ was analyzed in all the patients. The toxicities are summarized in Table 3. The most prevalent anlotinibrelated side effects in the monotherapy group were hypertension (51.3\%), fatigue (47.7\%), anorexia (39.6\%), hand-foot 
Fig. 3 Kaplan-Meier curve for progression-free survival in the previously treated population (A) and subgroup analyses of progression-free survival (B). CI confidence interval; HR, hazard ratio

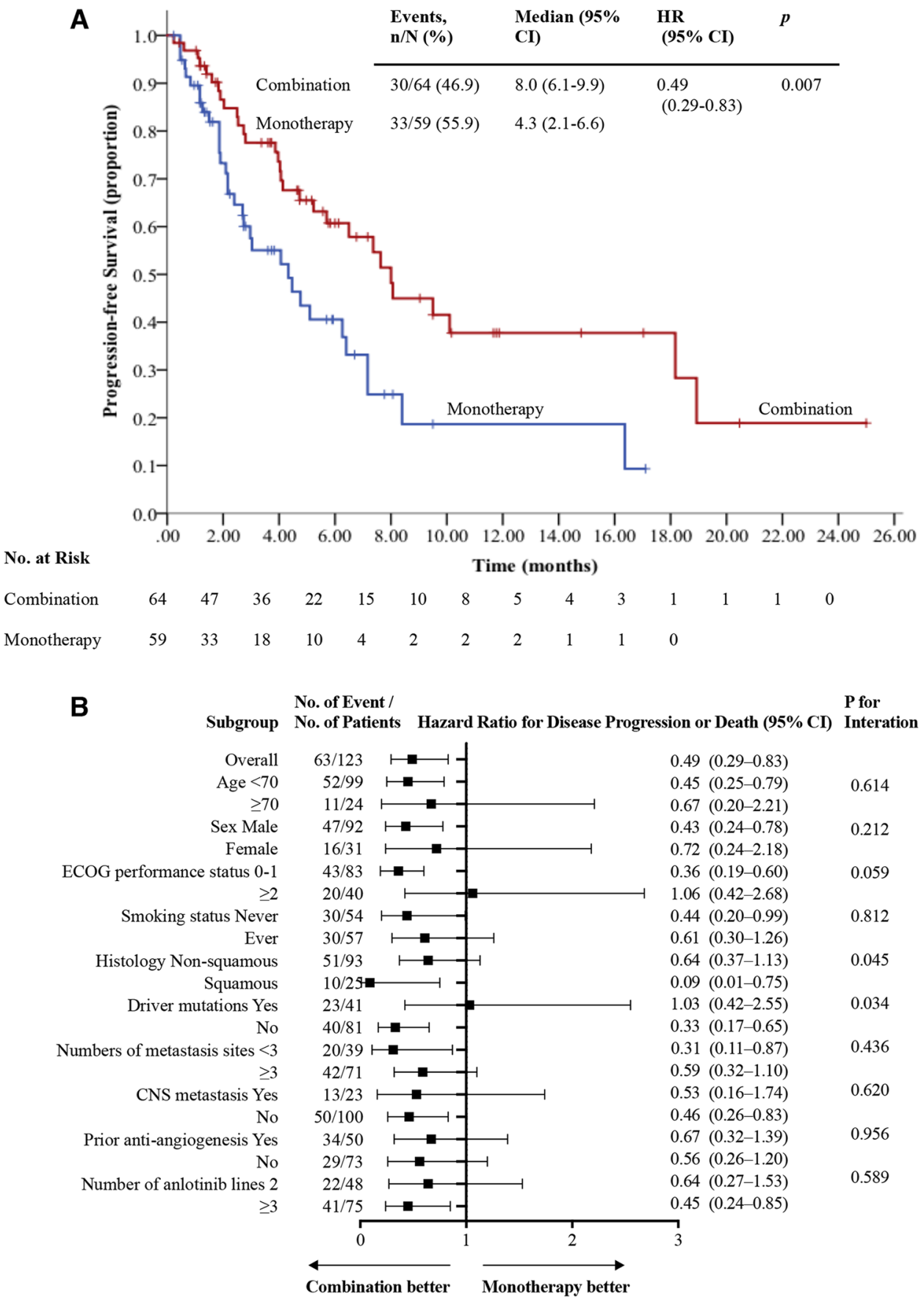

diarrhea (5.4 and 8.7\%), proteinuria (5.4 and 5.4\%), and oral mucositis (6.3 and $8.7 \%$, respectively). The only grade $\geq 3$ adverse event that was more frequent in the combination group was anorexia ( 8.7 and $0.9 \%$ ).

Dose reductions were required for five (4.5\%) patients in the monotherapy group, including four (3.6\%) cases of first-level reduction and one $(0.9 \%)$ case of second-level reduction. Dose reductions occurred in five (5.4\%) patients in the combination group (all one-level reductions). The suspension rates were $3.6 \%(4 / 111)$ and $6.5 \%(6 / 99)$ in the two groups, respectively. fatigue (8.1 and $7.6 \%$ ), hand-foot syndrome (8.1 and 6.5\%), 
Fig. 4 Kaplan-Meier curve for overall survival in the previously treated population (A) and subgroup analyses of overall survival (B). CI confidence interval, $H R$ hazard ratio

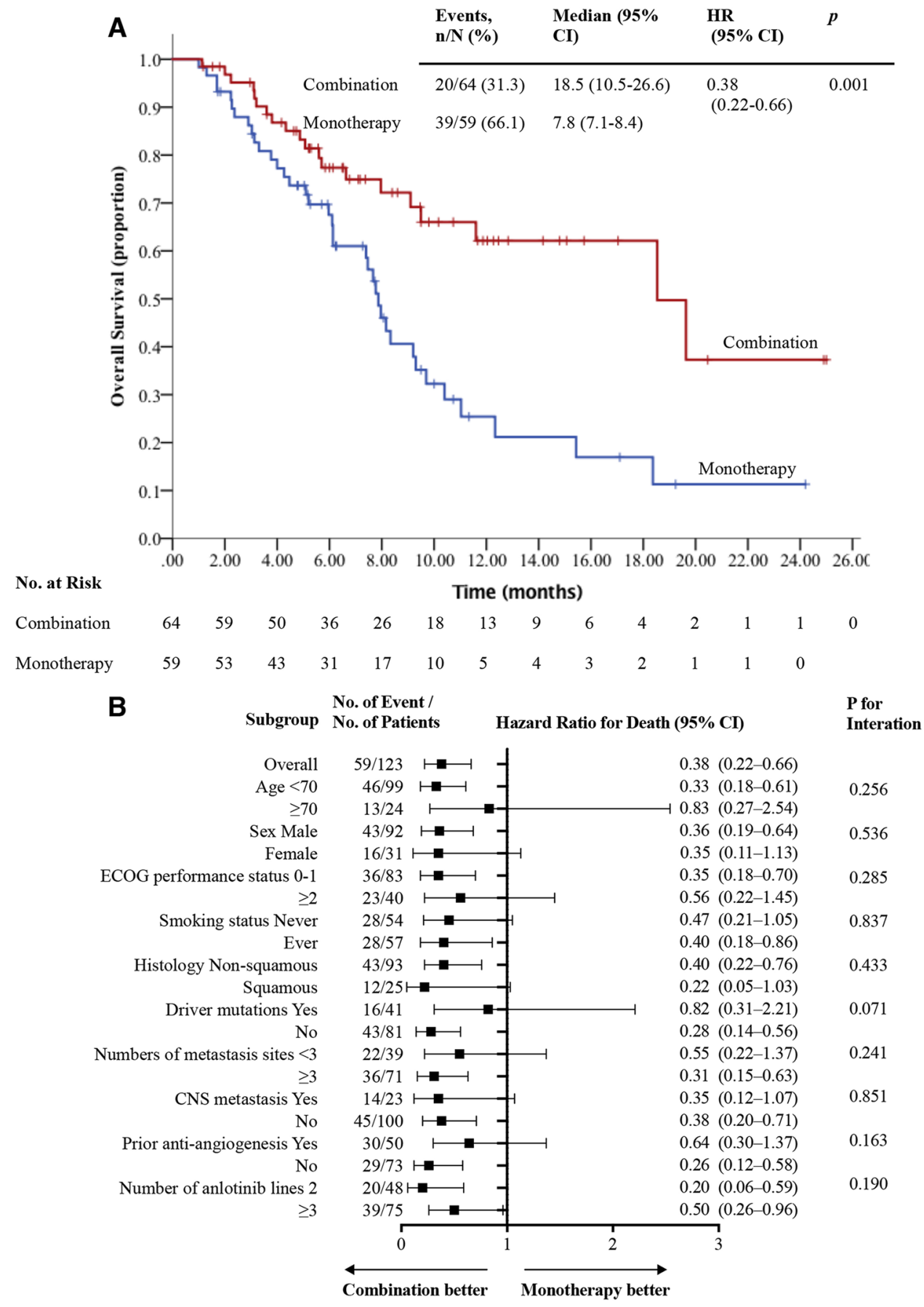

first-line (bevacizumab combination) (Patel et al. 2013; Reck et al. 2009; Sandler et al. 2006; Zhou et al. 2015) and laterline (ramucirumab combination) (Garon et al. 2014; Shiono et al. 2019) settings of aNSCLC, respectively. In multiple phase III trials, the combination of anti-VEGF monoclonal antibodies with erlotinib as first-line treatment significantly improved the PFS in patients with EGFR-mutant aNSCLC than erlotinib alone (Nakagawa et al. 2019; Saito et al. 2019; Zhou et al. 2019). However, multi-targeted TKIs that mainly block the VEGF signaling pathway have exhibited mixed 

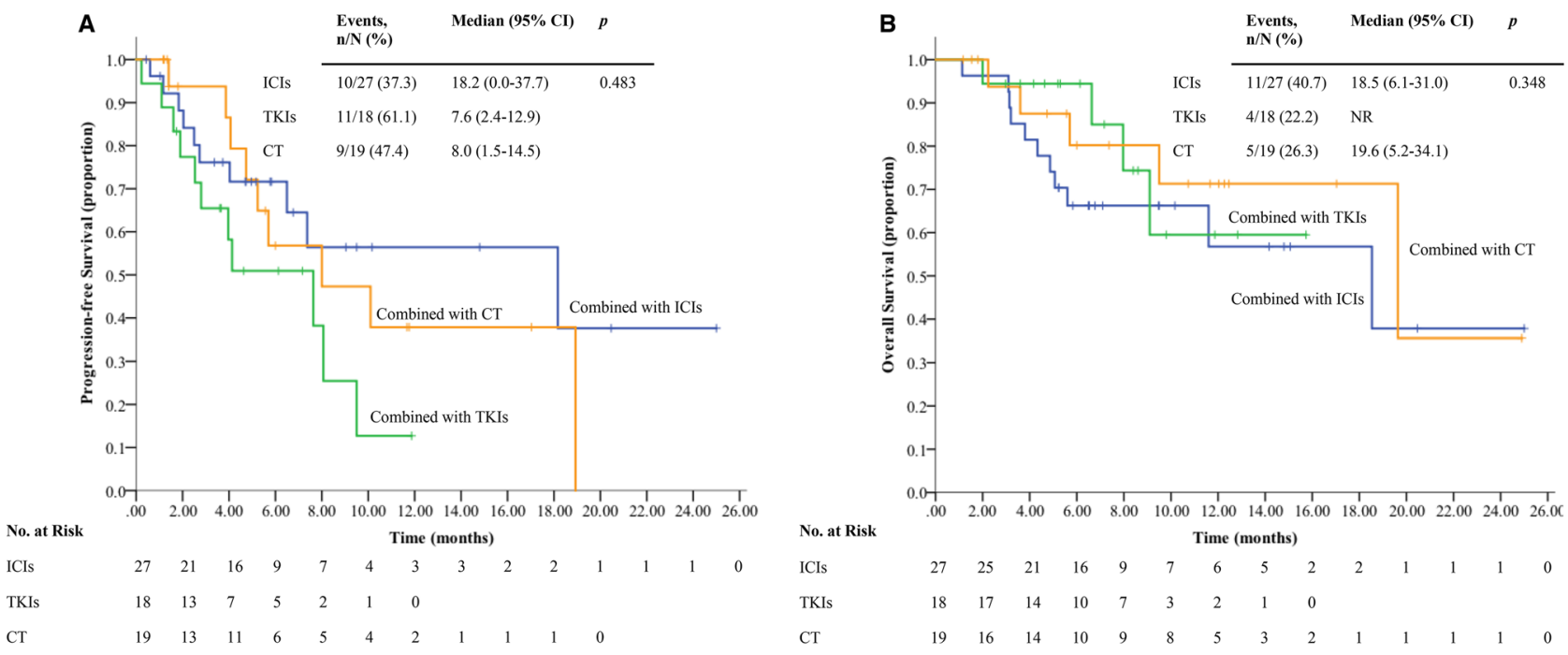

Fig. 5 Kaplan-Meier curve for progression-free survival (A) and overall survival (B) in the previously treated combination population. $C I$ confidence interval, $H R$ hazard ratio, $I C I$ immune checkpoint inhibitor, $T K I$ tyrosine kinase inhibitor, $C T$ chemotherapy

Table 2 Tumour response to treatment in two cohorts

\begin{tabular}{|c|c|c|c|c|c|c|}
\hline \multirow[t]{2}{*}{ Items } & \multicolumn{3}{|l|}{ Treatment-naïve cohort } & \multicolumn{3}{|l|}{ Previously treated cohort } \\
\hline & Monotherapy $(n=52)$ & Combination $(n=28)$ & $p$ & Monotherapy $(n=59)$ & Combination $(n=64)$ & $p$ \\
\hline \multicolumn{7}{|l|}{ Response, $n(\%)$} \\
\hline $\mathrm{CR}$ & $0(0)$ & $1(3.6)$ & & $0(0)$ & $1(1.6)$ & \\
\hline PR & $7(13.5)$ & $11(39.3)$ & & $4(6.8)$ & $18(28.1)$ & \\
\hline SD & $31(59.6)$ & $11(39.3)$ & & $31(52.5)$ & $33(51.6)$ & \\
\hline PD & $11(21.1)$ & $2(7.1)$ & & $22(27.3)$ & $12(18.8)$ & \\
\hline Missing/unevaluable & $3(5.8)$ & $3(10.7)$ & & $2(3.4)$ & $0(0)$ & \\
\hline ORR, $\%(95 \% \mathrm{CI})$ & $13.5(5.6,25.8)$ & $42.9(24.5,62.8)$ & 0.004 & $6.8(1.9,16.5)$ & $29.7(18.9,42.4)$ & 0.002 \\
\hline DCR, \% (95\% CI) & $73.1(59.0,84.4)$ & $82.1(63.1,93.9)$ & 0.197 & $59.3(45.8,71.9)$ & $81.3(69.5,89.9)$ & 0.025 \\
\hline
\end{tabular}

Clopper-Pearson method was used to calculate $95 \%$ CI of ORR or DCR

$C R$ complete response, $P R$ partial response, $S D$ stable disease, $P D$ progressive disease, $O R R$ objective response rate, $D C R$ disease control rate, $C I$ confidence interval

clinical activity in aNSCLC. Compared to placebo, these agents (e.g., vandetanib, pazopanib, sunitinib, and sorafenib) failed to improve survival in aNSCLC (Natale et al. 2011; Paz-Ares et al. 2015; Scagliotti et al. 2012a; Weiss et al. 2014). In combination with chemotherapy, unlike anlotinib, none of them had a superior efficacy to chemotherapy alone in aNSCLC (de Boer et al. 2011; Goss et al. 2010; Hanna et al. 2016; Herbst et al. 2010; Laurie et al. 2014; Lee et al. 2012; Paz-Ares et al. 2012; Reck et al. 2014; Scagliotti et al. 2010; Scagliotti et al. 2013; Scagliotti et al. 2012b). In the ALTER0303 trial, anlotinib greatly prolonged the $\mathrm{OS}$ and PFS than placebo. Anlotinib has a wide range of specific targets, including c-FMS, Aurora B, and discoidin domain receptor 1 (a group of newly identified kinase targets involved in tumor progression) (Sun et al. 2016), which might explain its positive results in aNSCLC. Likewise, the inhibitory action of these targets is responsible for anlotinib's anti-tumor and anti-angiogenic properties, which could explain its encouraging efficacy in the treatmentnaïve monotherapy group in our study. In previous clinical trials of first-line treatment in aNSCLC, bevacizumab plus chemotherapy significantly prolonged the PFS from 4.5 to 6-6.7 months, and OS from 10.3 to 12.3-13.4 months (Patel et al. 2013; Reck et al. 2009; Sandler et al. 2006). In our study, first-line anlotinib monotherapy demonstrated a comparable PFS (> 7 months) and slightly worse OS (approximate 11 months) than that of bevacizumab plus chemotherapy. These results may be due to the unique mechanism of anlotinib or the study population. Several patients in the treatment-naïve monotherapy group had wild-type mutations 
Table 3 Summary of toxicities in monotherapy and combination patients

\begin{tabular}{|c|c|c|c|c|}
\hline \multirow[t]{2}{*}{ Toxicity } & \multicolumn{2}{|c|}{$\begin{array}{l}\text { Monotherapy } \\
(n=111), \text { no. }(\%)\end{array}$} & \multicolumn{2}{|c|}{$\begin{array}{l}\text { Combination }(n=92) \text {, } \\
\text { no. }(\%)\end{array}$} \\
\hline & All grades & Grade $\geq 3$ & All grades & Grade $\geq 3$ \\
\hline \multicolumn{5}{|l|}{ Symptoms } \\
\hline Hypertension & $57(51.3)$ & $10(9.0)$ & $45(48.9)$ & $8(8.7)$ \\
\hline Fatigue & $53(47.7)$ & $9(8.1)$ & $66(71.7)$ & $7(7.6)$ \\
\hline Anorexia & $44(39.6)$ & $1(0.9)$ & $57(62.0)$ & $8(8.7)$ \\
\hline Hand-foot syndrome & $38(34.2)$ & $9(8.1)$ & $36(39.1)$ & $6(6.5)$ \\
\hline Cough & $36(32.4)$ & $3(2.7)$ & $27(29.3)$ & $0(0)$ \\
\hline Diarrhea & $34(30.6)$ & $6(5.4)$ & $40(43.5)$ & $8(8.7)$ \\
\hline Hypothyroidism & $33(29.7)$ & $4(3.6)$ & $36(39.1)$ & $3(3.3)$ \\
\hline Proteinuria & $33(29.7)$ & $6(5.4)$ & $25(27.2)$ & $5(5.4)$ \\
\hline Mucositis oral & $28(25.2)$ & $7(6.3)$ & $42(45.7)$ & $8(8.7)$ \\
\hline Hemorrhage & $27(24.3)$ & $4(3.6)$ & $22(23.9)$ & $4(4.3)$ \\
\hline Pharyngalgia & $25(22.5)$ & $1(0.9)$ & $23(25.0)$ & $0(0)$ \\
\hline Vomiting & $16(14.4)$ & $1(0.9)$ & $22(23.9)$ & $3(3.3)$ \\
\hline Weight loss & $15(13.5)$ & $0(0)$ & $10(10.9)$ & $0(0)$ \\
\hline Nausea & $13(11.7)$ & $1(0.9)$ & $20(21.7)$ & $3(3.3)$ \\
\hline Rash & $11(9.9)$ & $0(0)$ & $47(51.1)$ & $3(3.3)$ \\
\hline Hoarseness & $11(9.9)$ & $0(0)$ & $9(9.7)$ & $1(1.1)$ \\
\hline Dyspnea & $9(8.1)$ & $1(0.9)$ & $11(11.9)$ & $0(0)$ \\
\hline Headache & $9(8.1)$ & $0(0)$ & $9(9.7)$ & $0(0)$ \\
\hline Dizziness & $6(5.4)$ & $2(1.8)$ & $6(6.5)$ & $1(1.1)$ \\
\hline Abdominal pain & $6(5.4)$ & $1(0.9)$ & $5(5.4)$ & $2(2.2)$ \\
\hline Constipation & $5(4.5)$ & $1(0.9)$ & $7(7.6)$ & $0(0)$ \\
\hline Conjunctivitis & $3(2.7)$ & $0(0)$ & $12(13.0)$ & $1(1.1)$ \\
\hline Tinnitus & $2(1.8)$ & $0(0)$ & $3(3.3)$ & $0(0)$ \\
\hline Palpitation & $1(0.9)$ & $0(0)$ & $3(3.3)$ & $0(0)$ \\
\hline \multicolumn{5}{|l|}{$\begin{array}{l}\text { Laboratory examina- } \\
\text { tion }\end{array}$} \\
\hline Pneumonitis & $2(1.8)$ & $0(0)$ & $7(7.6)$ & $3(3.3)$ \\
\hline Hyperbilirubinemia & $10(9.0)$ & $0(0)$ & $20(21.7)$ & $2(2.2)$ \\
\hline AST elevation & $9(8.1)$ & $0(0)$ & $19(20.7)$ & $4(4.3)$ \\
\hline Hyponatremia & $8(7.2)$ & $1(0.9)$ & $10(10.9)$ & $0(0)$ \\
\hline Creatinine elevation & $7(6.3)$ & $0(0)$ & $8(8.7)$ & $0(0)$ \\
\hline ALT elevation & $6(5.4)$ & $0(0)$ & $22(23.9)$ & $3(3.3)$ \\
\hline Hypokalemia & $4(3.6)$ & $1(0.9)$ & $8(8.7)$ & $1(1.1)$ \\
\hline Hypoalbuminemia & $4(3.6)$ & $0(0)$ & $4(4.3)$ & $0(0)$ \\
\hline CKMB elevation & $4(3.6)$ & $1(0.9)$ & $6(6.5)$ & $1(1.1)$ \\
\hline Thrombocytopenia & $4(3.6)$ & $0(0)$ & $28(30.4)$ & $4(4.3)$ \\
\hline Anemia & $1(0.9)$ & $0(0)$ & $15(16.3)$ & $2(2.2)$ \\
\hline Neutropenia & $1(0.9)$ & $0(0)$ & $30(32.6)$ & $2(2.2)$ \\
\hline Leukopenia & $1(0.9)$ & $0(0)$ & $35(38.0)$ & $3(3.3)$ \\
\hline \multicolumn{5}{|l|}{ Dose modification } \\
\hline \multirow[t]{2}{*}{ Dose reduction } & 1 level & 2 level & 1 level & 2 level \\
\hline & $4(3.6)$ & $1(0.9)$ & $5(5.4)$ & $0(0)$ \\
\hline Suspension & $4(3.6)$ & & $6(6.5)$ & \\
\hline
\end{tabular}

and squamous cell carcinomas, which do not respond effectively to first-line targeted therapy. However, no clinical characteristic, including histology and diver mutations, was significantly associated with PFS or OS in this group. This is consistent with the ALTER0303 trial wherein anlotinib was effective for EGFR-mutant and wild-type patients (Han et al. 2018), with a significant improvement in the PFS, but not OS of patients with squamous cell carcinomas. The fibroblast growth factor (FGF) signaling pathway plays a key role in squamous cell lung cancer by promoting tumor cell proliferation and cancer angiogenesis through several mechanisms (Helsten et al. 2015; Procopio et al. 2015; Tiseo et al. 2015). As against FGF receptor, the efficacy of anlotinib in this population can be explained. Of note, anlotinib was administered to a population with a heavy tumor burden and adverse prognosis in our study (30-40\% of patients were $\geq 75$-years old, had ECOG PS $\geq 2$ or multiple metastases). Thus, the therapeutic effect of anlotinib may be undervalued because of the recipients' poor conditions and shorter life expectancy. Moreover, the limited rescue treatment in this population might have contributed to the shorter OS than that of standard bevacizumab-containing chemotherapy. Anlotinib monotherapy has less survival benefits as first-line treatment than immunochemotherapy (Gadgeel et al. 2020; Gandhi et al. 2018), especially in terms of OS. Nevertheless, according to our findings, anlotinib may still be an appropriate choice for patients with advanced age, poor PS, or reluctance to receive chemotherapy.

Anti-angiogenesis therapy can normalize abnormal vascularization in tumors, improve delivery of anti-tumor agents (Alshangiti et al. 2018), modify the immunosuppressive microenvironment, and crosslink with the EGFR signaling pathway (Tian et al. 2020); and thus play a synergistic antitumor role when combined with other treatments including chemotherapy, EGFR/TKIs, and ICIs. Additionally, the good tolerance and non-overlapping toxicity spectrum of anlotinib makes it possible to be combined. In the previously treated cohort in our study, anlotinib combination therapy improved survival and tumor response to monotherapy. The ECOG PS of the enrolled patients was different between the two groups, which may be a cause of bias. However, it did not show significant association with the survival. Prior anti-angiogenesis therapy was also different between the two groups; and it was significantly associated with PFS, but not OS in the multivariate analysis. However, the PFS benefit of the combination was observed in the subgroups with or without previous anti-angiogenic therapy, although the upper limit of the $95 \%$ CI exceeded 1 . These findings are consistent with those in earlier studies, which showed that previous anti-angiogenic therapy had no influence on PFS and OS of $\geq$ third-line anlotinib treatment in aNSCLC (Han et al. 2018; Shao et al. 2019; Zhang et al. 2020). 
The patients with squamous cell carcinoma and without driver mutations had a greater chance of improved PFS following combination therapy, with a $p$ value for interaction $\leq 0.05$. In the ALTER0303 trial, anlotinib had no additional therapeutic advantage in patients with squamous cell carcinoma or without driver mutations; therefore, we assume that the drugs in the combination may explain this difference. A considerable proportion of patients in the two subgroups (non-squamous vs. squamous, $36 \%$ vs. $0 \%$; driver mutations yes vs. no, $63 \%$ vs. $2.7 \%$ ) received anlotinib combined with original EGFR-TKIs as rescue therapy, immediately after the treatment failure with front-line EGFR-TKIs, which might only lead to modest survival benefits. In contrast, survival benefits were significant in patients with squamous cell carcinoma and wild-type mutations, most of who switched from later-line therapy to a combination with chemotherapy or immunotherapy. In the survival analysis with combined agents as the stratification factor, patients who received the EGFR-TKI combination had the shortest PFS, but the difference was not statistically significant. Several studies have compared erlotinib plus bevacizumab with erlotinib alone as first-line treatment in EGFR-mutant aNSCLC; PFS was improved, but not OS (Kato et al. 2018; Maemondo et al. 2020; Saito et al. 2019; Zhou et al. 2019). Consistently, the first-line combination of anlotinib with EGFR-TKIs has been reported to have an extremely high ORR and DCR in patients with EGFR-mutant aNSCLC (Huang et al. 2020a). Although there is no evidence that adding anti-angiogenesis therapy can improve survival after first-line EGFR-TKI resistance, this combination strategy has still been attempted in patients with slow disease progression in clinical practice. A study on the efficacy of anlotinib combined with first-generation (1G) EGFR-TKIs as second-line therapy in patients with secondary resistance to prior $1 \mathrm{G}$ EGFR-TKIs and nonT790M mutations in aNSCLC is ongoing (NCT03766490).

The efficacy of anlotinib combination therapy in aNSCLC was promising in previous studies, with an ORR of $60-92.6 \%$ in the first-line setting and $26-37.5 \%$ in the second-line setting (Han et al. 2019; Huang et al. 2020a; Wu et al. 2020). Due to the short follow-up time, the PFS was about 5 months in the patients who received anlotinib plus chemotherapy as $\geq$ second-line treatment in only two studies (Wu et al. 2020; Zhang et al. 2020). This was consistent with our study wherein anlotinib combination therapy had a better tumor response than monotherapy in both the treatment-naïve and previously treated patients; this effect was successfully translated into survival benefits in previously treated patients (the survival was immature in treatment-naïve patients). Anlotinib plus ICIs yielded the longest PFS among three different combinations in our study, although the differences were not statistically significant due to the small sample size. This finding supports the hypothesis of the synergistic effect of anti-angiogenic therapy and immunotherapy, which is likely through significant improving the migration of antigen-specific $\mathrm{T}$ cell by the vascular normalization (Wallin et al. 2016). This good survival is comparable to those reported in two recent studies on the combination of anlotinib with ICIs, with a PFS of 15 months in patients with untreated wild-type aNSCLC and an OS of 15.97 months in patients with previously treated EGFRmutant aNSCLC, respectively (Chen et al. 2021; Chu et al. 2021).

Even with imaging findings of disease progression, patients receiving anlotinib were permitted to continue. This was based on the following considerations. First, the RECIST criteria, which were developed from and validated by the data of clinical trials of cytotoxic chemotherapy has certain limitations in evaluating the efficacy of angiogenesis inhibitors (Grothey et al. 2008; van Klaveren et al. 2004). Different from cytotoxic chemotherapy that targets tumor cells, anti-angiogenic agents act on tumor vessels and likely induce tumor cavitation and density changes, instead of shrinkage (Chen et al. 2020; Jiang et al. 2019). Thus, the activity of anti-angiogenic therapy could be underestimated by the RECIST criteria if the efficacy is assessed simply using the change in tumor diameter. Second, preclinical studies have proven that prolonged exposure to anti-VEGF treatment beyond the discontinuation of cytotoxic agents may improve tumor control by delaying progression (Bagri et al. 2010). This is consistent with the modest clinical benefits of bevacizumab use after progression in different malignancies including aNSCLC (Bennouna et al. 2013; Gridelli et al. 2018; Takeda et al. 2012; von Minckwitz et al. 2014). Third, multiple studies have demonstrated that continuing targeted therapy could still improve survival in patients with slow progressive or oligometastatic/oligoprogressive aNSCLC (Le et al. 2018; Park et al. 2016). In our study, anlotinib was re-administered only when a minimum of two investigators confirmed that patients could benefit from cumulative anlotinib use after progression without symptomatic deterioration and unacceptable toxicity.

Generally, the safety profile of anlotinib combination therapy was comparable to that of monotherapy in terms of the frequency of $\geq$ grade 3 treatment-related adverse events and dose modification. The side effects in our study were in accordance with those in prior studies (Han et al. 2018; Huang et al. 2020; Wu et al. 2020; Zhang et al. 2020). There were no new safety concerns or anlotinib-related deaths.

The identification of predictive and prognostic factors of anti-angiogenic treatment is challenging. In our exploratory analysis, the PFS and OS were improved significantly in patients with higher baseline LMRs in the anlotinib monotherapy group, suggesting that LMR might be a predictor of the efficacy of anlotinib in this setting. LMR is a prognostic factor in lung cancer (Chen et al. 2015; Go et al. 2014; Hu et al. 2014; Song et al. 2016). Decreased LMR was shown 
to have significantly negative correlation with PFS and OS in bevacizumab treatment in aNSCLC (Li et al. 2019). The reason for this is unknown. We hypothesized that fewer circulating monocytes may reflect the limited formation or presence of tumor-associated macrophages (Clear et al. 2010; Lin et al. 2011); the latter has a positive relationship with extracellular matrix remodeling, angiogenesis, and lymphangiogenesis (Clear et al. 2010; Lin et al. 2006). Conversely, lymphocytopenia is an important component of low LMR; it induces fewer tumor-infiltrating lymphocytes for tumor cell eradication, which is associated with worse efficacy and survival in multiple malignancies (Chen et al. 2012); and it is also correlated with vascular invasion in NSCLC (Kobayashi et al. 2012). Therefore, a high LMR may reflect less angiogenesis, lymphangiogenesis, and vascular invasion, which may facilitate anlotinib treatment. Consistent with previous studies (Hong et al. 2015; $\mathrm{Li}$ et al. 2018), PNI was an independent prognostic factor in patients with aNSCLC who received anlotinib first-line monotherapy in our study. A high PNI is associated with an adequate anticancer immunological reaction, and functional and nutritional status of the host, which can enhance the tolerance and compliance to the treatment in patients with cancer (Deme and Telekes 2018; Fruchtenicht et al. 2015; Paccagnella et al. 2011). Although this is an exploratory and post hoc analysis, these markers are readily available and inexpensive in clinical practice; they could help to predict the efficacy of anlotinib and estimate the prognosis once our results are validated in future studies.

Our study has a few limitations beyond the retrospective design and consequent selection bias. First, as a real-world study, the non-diverse Chinese population and the small sample size might have affected the generalizability of the results; however, a rigorous approach was used to minimize the chances for error and bias, which entailed centralized reviewing of the radiological responses and independent monitoring. A prospective multi-center observational study with a larger sample size is being planned to further confirm the results of the current study. Second, the monotherapy and combination groups were clinically heterogeneous; however, the multivariate Cox regression analysis was used to adjust for confounding factors. Third, we were unable to obtain the survival of the first-line combination group due to the short follow-up duration.

Nevertheless, our study has several advantages. First, the best strategy for utilizing agents with different mechanisms of action in aNSCLC remains controversial. Our study provides an attractive alternative chemotherapy-free strategy for the first-line treatment of patients with aNSCLC, especially for those who are frail, have a poor performance status, and are unwilling or unable to receive chemotherapy or immunotherapy. Second, in this era when first-line immunotherapy \pm chemotherapy is the standard care for patients without driver mutations, our study provides additional evidence for the application of second-line anti-angiogenesis combination therapy. Third, we further explored the potential predictive and prognostic factors of anlotinib monotherapy for untreated aNSCLC, which can serve as baseline data for further studies on biomarkers of anti-angiogenic therapy. Finally, the convenience and feasibility of anlotinib, especially during the COVID19 pandemic, makes our findings generalizable.

\section{Conclusions}

Anlotinib monotherapy has a promising efficacy in the firstline setting. It may be an option for patients with aNSCLC who are ineligible for chemotherapy in the real world. Anlotinib plus other anti-tumor regimens in $\mathrm{a} \geq$ second-line setting showed manageable toxicities and encouraging efficacy, indicating a good application prospect in aNSCLC. Our conclusion would benefit from the addition of information on the scope for further research on the topic.

Supplementary information The online version contains supplementary material available at https://doi.org/10.1007/s00432-021-03752-x.

Acknowledgements We would like to thank Editage (http://www.edita ge.cn) for English editing.

Author contributions FW: conceptualization, methodology, investigation, writing - review and editing. FJ: investigation, writing-review and editing. BC: investigation, writing — review and editing. YZ: methodology, investigation. QZ: conceptualization, methodology, investigation, writing - review and editing. SW: conceptualization, methodology, investigation, writing — review and editing.

Funding This study was funded by the Wu Jieping Medical Foundation (320.6750.19088-10), Beijing Bethune Charitable Foundation (BQE-TY-SSPC(2)-S-01), and Shenzhen Sanming Project (SZSM201612041).

Availability of data and material The datasets analyzed during the current study can be obtained from the corresponding author on reasonable requirements.

\section{Declarations}

Conflict of interest Dr. Qing Zhou reports speaker fees from AstraZeneca and Roche. The other authors indicate no conflicts of interest.

Ethics approval The study was approved by the China Ethics Committee of Registering Clinical Trials (No. ChiECRCT20200083) and performed in accordance with Good Clinical Practice and the provisions of the Declaration of Helsinki.

Consent to participate Written informed consent was waived given the nature of the study.

Consent for publication Informed consent was obtained from the authors. 


\section{References}

Alshangiti A, Chandhoke G, Ellis PM (2018) Antiangiogenic therapies in non-small-cell lung cancer. Curr Oncol 25:S45-S58. https://doi. org $/ 10.3747 /$ co. 25.3747

Bagri A et al (2010) Effects of anti-VEGF treatment duration on tumor growth, tumor regrowth, and treatment efficacy. Clin Cancer Res 16:3887-3900. https://doi.org/10.1158/1078-0432.CCR-09-3100

Barlesi F et al (2014) Maintenance bevacizumab-pemetrexed after first-line cisplatin-pemetrexed-bevacizumab for advanced nonsquamous nonsmall-cell lung cancer: updated survival analysis of the AVAPERL (MO22089) randomized phase III trial. Ann Oncol 25:1044-1052. https://doi.org/10.1093/annonc/mdu098

Bennouna J et al (2013) Continuation of bevacizumab after first progression in metastatic colorectal cancer (ML18147): a randomised phase 3 trial. Lancet Oncol 14:29-37. https://doi.org/10.1016/ S1470-2045(12)70477-1

Chen KJ, Zhou L, Xie HY, Ahmed TE, Feng XW, Zheng SS (2012) Intratumoral regulatory $\mathrm{T}$ cells alone or in combination with cytotoxic $\mathrm{T}$ cells predict prognosis of hepatocellular carcinoma after resection. Med Oncol 29:1817-1826. https://doi.org/10.1007/ s12032-011-0006-X

Chen YM et al (2015) Baseline and trend of lymphocyte-to-monocyte ratio as prognostic factors in epidermal growth factor receptor mutant non-small cell lung cancer patients treated with firstline epidermal growth factor receptor tyrosine kinase inhibitors. PLoS One 10:e0136252. https://doi.org/10.1371/journal.pone. 0136252

Chen D, Xu J, Zhao Y, Chu T, Zhong H, Han B, Zhong R (2020) Prognostic value of tumor cavitation in extensive-stage small-cell lung cancer patients treated with anlotinib. J Cancer Res Clin Oncol 146:401-406. https://doi.org/10.1007/s00432-019-03064-1

Chen Y et al (2021) Pembrolizumab plus chemotherapy or anlotinib vs. pembrolizumab alone in patients with previously treated EGFRmutant NSCLC. Front Oncol 11:671228. https://doi.org/10.3389/ fonc. 2021.671228

Cheng Y et al (2018) Anlotinib as third-line or further-line treatment in relapsed SCLC: a multicentre, randomized, double-blind phase 2 trial. J Thorac Oncol 13:S351-S352

Chu T et al (2021) Phase 1b study of sintilimab plus anlotinib as firstline therapy in patients with advanced NSCLC. J Thorac Oncol 16:643-652. https://doi.org/10.1016/j.jtho.2020.11.026

Clear AJ et al (2010) Increased angiogenic sprouting in poor prognosis FL is associated with elevated numbers of CD163+ macrophages within the immediate sprouting microenvironment. Blood 115:5053-5056. https://doi.org/10.1182/blood-2009-11-253260

de Boer RH et al (2011) Vandetanib plus pemetrexed for the secondline treatment of advanced non-small-cell lung cancer: a randomized, double-blind phase III trial. J Clin Oncol 29:1067-1074. https://doi.org/10.1200/JCO.2010.29.5717

Deme D, Telekes A (2018) Prognostic importance of albumin in oncology. Orv Hetil 159:96-106. https://doi.org/10.1556/650.2018. 30885

Eisenhauer EA et al (2009) New response evaluation criteria in solid tumours: revised RECIST guideline (version 1.1). Eur J Cancer 45:228-247. https://doi.org/10.1016/j.ejca.2008.10.026

Fossella F et al (2003) Randomized, multinational, phase III study of docetaxel plus platinum combinations versus vinorelbine plus cisplatin for advanced non-small-cell lung cancer: the TAX 326 study group. J Clin Oncol 21:3016-3024. https://doi.org/10.1200/ JCO.2003.12.046

Fruchtenicht AV, Poziomyck AK, Kabke GB, Loss SH, Antoniazzi JL, Steemburgo T, Moreira LF (2015) Nutritional risk assessment in critically Ill cancer patients: systematic review. Rev Bras Ter
Intensiv 27:274-283. https://doi.org/10.5935/0103-507X.20150 032

Gadgeel S et al (2020) Updated analysis from KEYNOTE-189: pembrolizumab or placebo plus pemetrexed and platinum for previously untreated metastatic nonsquamous non-small-cell lung cancer. J Clin Oncol 38:1505-1517. https://doi.org/10.1200/JCO.19. 03136

Gandhi L et al (2018) Pembrolizumab plus chemotherapy in metastatic non-small-cell lung cancer. N Engl J Med 378:2078-2092. https://doi.org/10.1056/NEJMoa1801005

Garon EB et al (2014) Ramucirumab plus docetaxel versus placebo plus docetaxel for second-line treatment of stage IV non-smallcell lung cancer after disease progression on platinum-based therapy (REVEL): a multicentre, double-blind, randomised phase 3 trial. Lancet 384:665-673. https://doi.org/10.1016/ S0140-6736(14)60845-X

Garon EB et al (2019) Five-year overall survival for patients with advanced nonsmall-cell lung cancer treated with pembrolizumab: results from the phase I KEYNOTE-001 study. J Clin Oncol 37:2518-2527. https://doi.org/10.1200/JCO.19.00934

Gettinger S et al (2018) Five-year follow-up of nivolumab in previously treated advanced non-small-cell lung cancer: results from the CA209-003 study. J Clin Oncol 36:1675-1684. https://doi. org/10.1200/JCO.2017.77.0412

Go SI et al (2014) Prognostic significance of the lymphocyte-tomonocyte ratio in patients with small cell lung cancer. Med Oncol 31:323. https://doi.org/10.1007/s12032-014-0323-y

Goss GD et al (2010) Randomized, double-blind trial of carboplatin and paclitaxel with either daily oral cediranib or placebo in advanced non-small-cell lung cancer: NCIC clinical trials group BR24 study. J Clin Oncol 28:49-55. https://doi.org/10.1200/ JCO.2009.22.9427

Gridelli C et al (2018) Safety and efficacy of bevacizumab plus standard-of-care treatment beyond disease progression in patients with advanced non-small cell lung cancer: the AvaALL randomized clinical trial. JAMA Oncol 4:e183486. https://doi. org/10.1001/jamaoncol.2018.3486

Grothey A et al (2008) Response-independent survival benefit in metastatic colorectal cancer: a comparative analysis of N9741 and AVF2107. J Clin Oncol 26:183-189. https://doi.org/10. 1200/JCO.2007.13.8099

Han B et al (2018) Effect of anlotinib as a third-line or further treatment on overall survival of patients with advanced non-small cell lung cancer: the ALTER 0303 phase 3 randomized clinical trial. JAMA Oncol 4:1569-1575. https://doi.org/10.1001/jamao ncol.2018.3039

Han B, Chu T, Zhong R, Zhong H, Zhang B, Zhang W, Shi C, Qian J, Han Y (2019) JCSE01.11 Efficacy and safety of sintilimab with anlotinib as first-line therapy for advanced non-small cell lung cancer (NSCLC). J Thorac Oncol 14(10):S129. https://doi. org/10.1016/j.jtho.2019.08.269

Hanna NH et al (2016) Nintedanib plus pemetrexed versus placebo plus pemetrexed in patients with relapsed or refractory, advanced non-small cell lung cancer (LUME-Lung 2): a randomized, double-blind, phase III trial. Lung Cancer 102:65-73. https://doi.org/10.1016/j.lungcan.2016.10.011

Helsten T, Schwaederle M, Kurzrock R (2015) Fibroblast growth factor receptor signaling in hereditary and neoplastic disease: biologic and clinical implications. Cancer Metastasis Rev 34:479-496. https://doi.org/10.1007/s10555-015-9579-8

Herbst RS et al (2010) Vandetanib plus docetaxel versus docetaxel as second-line treatment for patients with advanced non-small-cell lung cancer (ZODIAC): a double-blind, randomised, phase 3 trial. Lancet Oncol 11:619-626. https://doi.org/10.1016/S14702045(10)70132-7 
Hong S et al (2015) The prognostic nutritional index (PNI) predicts overall survival of small-cell lung cancer patients. Tumour Biol 36:3389-3397. https://doi.org/10.1007/s13277-014-2973-y

Hu P, Shen H, Wang G, Zhang P, Liu Q, Du J (2014) Prognostic significance of systemic inflammation-based lymphocyte-monocyte ratio in patients with lung cancer: based on a large cohort study. PLoS ONE 9:e108062. https://doi.org/10.1371/journal. pone. 0108062

Huang D, Zhong D, Zhang C, Zhang Y, Shang Y, Wang L (2020a) Study of anlotinib combined with icotinib as the first-line treatment in non-small cell lung cancer (NSCLC) patients harboring activating EGFR mutations (ALTER-L004). J Clin Oncol 38:9573-9573. https://doi.org/10.1200/JCO.2020.38.15_suppl. 9573

Jiang M et al (2019) Influence and mechanism of lung cavitation development on antiangiogenic therapy. Transl Lung Cancer Res 8:500-512. https://doi.org/10.21037/tlcr.2019.07.01

Kato T et al (2018) Erlotinib plus bevacizumab phase 11 study in patients with advanced non-small-cell lung cancer (JO25567): updated safety results. Drug Saf 41:229-237. https://doi.org/10. 1007/s40264-017-0596-0

Kobayashi N, Usui S, Kikuchi S, Goto Y, Sakai M, Onizuka M, Sato Y (2012) Preoperative lymphocyte count is an independent prognostic factor in node-negative non-small cell lung cancer. Lung Cancer 75:223-227. https://doi.org/10.1016/j.lungcan.2011.06.009

Laurie SA et al (2014) Randomised, double-blind trial of carboplatin and paclitaxel with daily oral cediranib or placebo in patients with advanced non-small cell lung cancer: NCIC Clinical Trials Group study BR29. Eur J Cancer 50:706-712. https://doi.org/10.1016/j. ejca.2013.11.032

Le $X$ et al (2018) Landscape of EGFR-dependent and -independent resistance mechanisms to osimertinib and continuation therapy beyond progression in EGFR-mutant NSCLC. Clin Cancer Res 24:6195-6203. https://doi.org/10.1158/1078-0432.CCR-18-1542

Lee JS et al (2012) Vandetanib Versus placebo in patients with advanced non-small-cell lung cancer after prior therapy with an epidermal growth factor receptor tyrosine kinase inhibitor: a randomized, double-blind phase III trial (ZEPHYR). J Clin Oncol 30:1114-1121. https://doi.org/10.1200/JCO.2011.36.1709

Li D, Yuan X, Liu J, Li C, Li W (2018) Prognostic value of prognostic nutritional index in lung cancer: a meta-analysis. J Thorac Dis 10:5298-5307. https://doi.org/10.21037/jtd.2018.08.51

Li B et al (2019) The kinetic changes of systemic inflammatory factors during bevacizumab treatment and its prognostic role in advanced non-small cell lung cancer patients. J Cancer 10:5082-5089. https://doi.org/10.7150/jca.30478

Lin EY et al (2006) Macrophages regulate the angiogenic switch in a mouse model of breast cancer. Cancer Res 66:11238-11246. https://doi.org/10.1158/0008-5472.CAN-06-1278

Lin JY, Li XY, Tadashi N, Dong P (2011) Clinical significance of tumor-associated macrophage infiltration in supraglottic laryngeal carcinoma. Chin J Cancer 30:280-286. https://doi.org/10.5732/ cjc. 010.10336

Lin JJ, Cardarella S, Lydon CA, Dahlberg SE, Jackman DM, Janne PA, Johnson BE (2016) Five-year survival in EGFR-mutant metastatic lung adenocarcinoma treated with EGFR-TKIs. J Thorac Oncol 11:556-565. https://doi.org/10.1016/j.jtho.2015.12.103

Lin B, Song X, Yang D, Bai D, Yao Y, Lu N (2018) Anlotinib inhibits angiogenesis via suppressing the activation of VEGFR2, PDGFRbeta and FGFR1. Gene 654:77-86. https://doi.org/10.1016/j. gene.2018.02.026

Maemondo $M$ et al (2020) NEJ026: final overall survival analysis of bevacizumab plus erlotinib treatment for NSCLC patients harboring activating EGFR-mutations. J Clin Oncol 38:9506-9506. https://doi.org/10.1200/JCO.2020.38.15_suppl.9506
Miller KD et al (2019) Cancer treatment and survivorship statistics, 2019. CA Cancer J Clin 69:363-385. https://doi.org/10.3322/ caac. 21565

Mok TS et al (2009) Gefitinib or carboplatin-paclitaxel in pulmonary adenocarcinoma. N Engl J Med 361:947-957. https://doi.org/10. 1056/NEJMoa0810699

Nabhan C, Klink A, Prasad V (2019) Real-world evidence-what does it really mean? JAMA Oncol 5:781-783. https://doi.org/10.1001/ jamaoncol.2019.0450

Nakagawa K et al (2019) Ramucirumab plus erlotinib in patients with untreated, EGFR-mutated, advanced non-small-cell lung cancer (RELAY): a randomised, double-blind, placebo-controlled, phase 3 trial. Lancet Oncol 20:1655-1669. https://doi.org/10.1016/ S1470-2045(19)30634-5

Natale RB et al (2011) Phase III trial of vandetanib compared with erlotinib in patients with previously treated advanced non-smallcell lung cancer. J Clin Oncol 29:1059-1066. https://doi.org/10. 1200/JCO.2010.28.5981

Paccagnella A, Morassutti I, Rosti G (2011) Nutritional intervention for improving treatment tolerance in cancer patients. Curr Opin Oncol 23:322-330. https://doi.org/10.1097/CCO.0b013e3283479c66

Park K et al (2016) First-line erlotinib therapy until and beyond response evaluation criteria in solid tumors progression in Asian patients with epidermal growth factor receptor mutation-positive non-small-cell lung cancer: the ASPIRATION study. JAMA Oncol 2:305-312. https://doi.org/10.1001/jamaoncol.2015.4921

Patel JD et al (2013) PointBreak: a randomized phase III study of pemetrexed plus carboplatin and bevacizumab followed by maintenance pemetrexed and bevacizumab versus paclitaxel plus carboplatin and bevacizumab followed by maintenance bevacizumab in patients with stage IIIB or IV nonsquamous non-small-cell lung cancer. J Clin Oncol 31:4349-4357. https://doi.org/10.1200/JCO. 2012.47.9626

Paz-Ares LG et al (2012) Phase III, randomized, double-blind, placebocontrolled trial of gemcitabine/cisplatin alone or with sorafenib for the first-line treatment of advanced, nonsquamous non-smallcell lung cancer. J Clin Oncol 30:3084-3092. https://doi.org/10. 1200/JCO.2011.39.7646

Paz-Ares L et al (2015) Monotherapy administration of sorafenib in patients with non-small cell lung cancer (MISSION) trial: a phase III, multicenter, placebo-controlled trial of sorafenib in patients with relapsed or refractory predominantly nonsquamous nonsmall-cell lung cancer after 2 or 3 previous treatment regimens. J Thorac Oncol 10:1745-1753. https://doi.org/10.1097/JTO.00000 00000000693

Procopio MG et al (2015) Combined CSL and p53 downregulation promotes cancer-associated fibroblast activation. Nat Cell Biol 17:1193-1204. https://doi.org/10.1038/ncb3228

Ramalingam SS et al (2020) Overall survival with osimertinib in untreated, EGFR-mutated advanced NSCLC. N Engl J Med 382:41-50. https://doi.org/10.1056/NEJMoa1913662

Reck M et al (2009) Phase III trial of cisplatin plus gemcitabine with either placebo or bevacizumab as first-line therapy for nonsquamous non-small-cell lung cancer: AVAil. J Clin Oncol 27:12271234. https://doi.org/10.1200/JCO.2007.14.5466

Reck M et al (2014) Docetaxel plus nintedanib versus docetaxel plus placebo in patients with previously treated non-small-cell lung cancer (LUME-Lung 1): a phase 3, double-blind, randomised controlled trial. Lancet Oncol 15:143-155. https://doi.org/10.1016/ S1470-2045(13)70586-2

Saito H et al (2019) Erlotinib plus bevacizumab versus erlotinib alone in patients with EGFR-positive advanced non-squamous non-small-cell lung cancer (NEJ026): interim analysis of an open-label, randomised, multicentre, phase 3 trial. Lancet Oncol 20:625-635. https://doi.org/10.1016/S1470-2045(19)30035-X 
Sandler A et al (2006) Paclitaxel-carboplatin alone or with bevacizumab for non-small-cell lung cancer. N Engl J Med 355:25422550. https://doi.org/10.1056/NEJMoa061884

Scagliotti GV et al (2008) Phase III study comparing cisplatin plus gemcitabine with cisplatin plus pemetrexed in chemotherapynaive patients with advanced-stage non-small-cell lung cancer. J Clin Oncol 26:3543-3551. https://doi.org/10.1200/JCO.2007. 15.0375

Scagliotti G et al (2010) Phase III study of carboplatin and paclitaxel alone or with sorafenib in advanced non-small-cell lung cancer. J Clin Oncol 28:1835-1842. https://doi.org/10.1200/JCO.2009. 26.1321

Scagliotti GV et al (2012a) Sunitinib plus erlotinib versus placebo plus erlotinib in patients with previously treated advanced non-smallcell lung cancer: a phase III trial. J Clin Oncol 30:2070-2078. https://doi.org/10.1200/JCO.2011.39.2993

Scagliotti GV et al (2012b) International, randomized, placebo-controlled, double-blind phase III study of motesanib plus carboplatin/paclitaxel in patients with advanced nonsquamous non-smallcell lung cancer: MONET1. J Clin Oncol 30:2829-2836. https:// doi.org/10.1200/JCO.2011.41.4987

Scagliotti GV et al (2013) An open-label, multicenter, randomized, phase II study of pazopanib in combination with pemetrexed in first-line treatment of patients with advanced-stage non-smallcell lung cancer. J Thorac Oncol 8:1529-1537. https://doi.org/ 10.1097/JTO.0000000000000005

Schiller JH et al (2002) Comparison of four chemotherapy regimens for advanced non-small-cell lung cancer. N Engl J Med 346:92-98. https://doi.org/10.1056/NEJMoa011954

Shao L, Wang W, Song Z, Zhang Y (2019) The efficacy and safety of anlotinib treatment for advanced lung cancer. Onco Targets Ther 12:6549-6554. https://doi.org/10.2147/OTT.S205674

Shiono A et al (2019) Improved efficacy of ramucirumab plus docetaxel after nivolumab failure in previously treated non-small cell lung cancer patients. Thorac Cancer 10:775-781. https://doi.org/10. 1111/1759-7714.12998

Siegel RL, Miller KD, Jemal A (2019) Cancer statistics, 2019. CA Cancer J Clin 69:7-34. https://doi.org/10.3322/caac.21551

Socinski MA, Nishio M, Jotte RM, Cappuzzo F, Orlandi F, Stroyakovskiy D, Nogami N, Rodríguez-Abreu D, Moro-Sibilot D, Thomas CA, Barlesi F, Finley G, Kong S, Lee A, Coleman S, Zou W, McCleland M, Shankar G, Reck M (2021) IMpower150 final overall survival analyses for atezolizumab plus bevacizumab and chemotherapy in first-line metastatic nonsquamous non-small cell lung cancer. J Thorac Oncol. https://doi.org/10.1016/j.jtho. 2021.07.009

Song YJ, Wang LX, Hong YQ, Lu ZH, Tong Q, Fang XZ, Tan J (2016) Lymphocyte to monocyte ratio is associated with response to firstline platinum-based chemotherapy and prognosis of early-stage non-small cell lung cancer patients. Tumour Biol 37:5285-5293. https://doi.org/10.1007/s13277-015-4397-8

Sun Y et al (2016) Safety, pharmacokinetics, and antitumor properties of anlotinib, an oral multi-target tyrosine kinase inhibitor, in patients with advanced refractory solid tumors. J Hematol Oncol 9:105. https://doi.org/10.1186/s13045-016-0332-8

Takeda M, Okamoto I, Yamanaka T, Nakagawa K, Nakanishi Y (2012) Impact of treatment with bevacizumab beyond disease progression: a randomized phase II study of docetaxel with or without bevacizumab after platinum-based chemotherapy plus bevacizumab in patients with advanced nonsquamous non-small cell lung cancer (WJOG 5910L). BMC Cancer 12:327. https://doi. org/10.1186/1471-2407-12-327
Tian W, Cao C, Shu L, Wu F (2020) Anti-angiogenic therapy in the treatment of non-small cell lung cancer. Onco Targets Ther 13:12113-12129. https://doi.org/10.2147/OTT.S276150

Tiseo M et al (2015) FGFR as potential target in the treatment of squamous non small cell lung cancer. Cancer Treat Rev 41:527-539. https://doi.org/10.1016/j.ctrv.2015.04.011

van Klaveren RJ, Aerts JG, de Bruin H, Giaccone G, Manegold C, van Meerbeeck JP (2004) Inadequacy of the RECIST criteria for response evaluation in patients with malignant pleural mesothelioma. Lung Cancer 43:63-69. https://doi.org/10.1016/s01695002(03)00292-7

von Minckwitz G et al (2014) Bevacizumab plus chemotherapy versus chemotherapy alone as second-line treatment for patients with HER2-negative locally recurrent or metastatic breast cancer after first-line treatment with bevacizumab plus chemotherapy (TANIA): an open-label, randomised phase 3 trial. Lancet Oncol 15:1269-1278. https://doi.org/10.1016/S1470-2045(14)70439-5

Wallin JJ et al (2016) Atezolizumab in combination with bevacizumab enhances antigen-specific T-cell migration in metastatic renal cell carcinoma. Nat Commun 7:12624. https://doi.org/10.1038/ncomm s12624

Wang Z, Wang Y, Zhang X, Zhang T (2018) Pretreatment prognostic nutritional index as a prognostic factor in lung cancer: review and meta-analysis. Clin Chim Acta 486:303-310. https://doi.org/10. 1016/j.cca.2018.08.030

Weiss JM, Villaruz LC, Socinski MA, Ivanova A, Grilley-Olson J, Dhruva N, Stinchcombe TE (2014) A single-arm phase II trial of pazopanib in patients with advanced non-small cell lung cancer with non-squamous histology with disease progression on bevacizumab containing therapy. Lung Cancer 86:288-290. https://doi. org/10.1016/j.lungcan.2014.08.011

Wu L et al (2020) A randomized phase II multi-institutional trial of anlotinib plus docetaxel versus docetaxel in EGFR-wild-type nonsmall cell lung cancer (NSCLC) patients after progression on firstline platinum-base chemotherapy: ALTER-L018. J Clin Oncol 38:e21703. https://doi.org/10.1200/JCO.2020.38.15_suppl.e21703

Xie C, Wan X, Quan H, Zheng M, Fu L, Li Y, Lou L (2018) Preclinical characterization of anlotinib, a highly potent and selective vascular endothelial growth factor receptor-2 inhibitor. Cancer Sci 109:1207-1219. https://doi.org/10.1111/cas.13536

Zhang K, Ma X, Gao H, Wang H, Qin H, Yang S, Liu X (2020) Efficacy and safety of anlotinib in advanced non-small cell lung cancer: a real-world study. Cancer Manag Res 12:3409-3417. https:// doi.org/10.2147/CMAR.S246000

Zhou C et al (2015) BEYOND: a randomized, double-blind, placebocontrolled, multicenter, phase III study of first-line carboplatin/ paclitaxel plus bevacizumab or placebo in Chinese patients with advanced or recurrent nonsquamous non-small-cell lung cancer. J Clin Oncol 33:2197-2204. https://doi.org/10.1200/JCO.2014. 59.4424

Zhou Q et al (2019a) 1480O-CTONG 1509: phase III study of bevacizumab with or without erlotinib in untreated Chinese patients with advanced EGFR-mutated NSCLC. Ann Oncol 30:v603. https:// doi.org/10.1093/annonc/mdz260.002

Publisher's Note Springer Nature remains neutral with regard to jurisdictional claims in published maps and institutional affiliations. 